\title{
Microbes on fish skin display distinct evolutionary patterns
}

Michael Doane Ph.D

Megan M. Morris

Bhavya Papudeshi

Lauren Allen

Dnyanada Pande

John M. Haggerty

Shaili Johri

Abby Turnland

Meredith Peterson

Dovi Kacev

Andy Nosal

Deni Ramirez

Kevin Hovel

Julia Ledbetter

Amanda Alker

Jackeline Avalos

Kristi Baker

Shruti Bhide

Emma Billings

Steven Byrum

Molly Clemens

Amelia Juliette Demery

Lais Farias Oliveira Lima

Oscar Gomez

Omar Gutierrez

Selena Hinton

Donald Kieu

Angie Kim

Rebeca Loaiza

Alexander Martinez

Jordan McGhee

Kristine Nguyen

Sabrina Parlan

Amanda Pham

Rosalyn Price-Waldman 
Robert A. Edwards

Elizabeth A. Dinsdale

\section{Video Byte}

Keywords: Microbiome, phylosymbiosis, metagenomics, elasmobranch, skin, teleost, vertebrate fishes, microbial community, community ecology, Chondrichthyes, Osteichthyes, shotgun metagenomics, clade, host-microbiome similarity, functional composition, assemblage, holobiont, cartilaginous, bony fish, denticle

Posted Date: October 28th, 2020

DOI: https://doi.org/10.21203/rs.3.rs-99202/v1

License: (c) (i) This work is licensed under a Creative Commons Attribution 4.0 International License. Read Full License 


\section{Abstract}

Microbiomes share an intimate relationship with the organisms they colonize, even across evolutionary timescales. That's the basis of a theory called phylosymbiosis. Phylosymbiosis holds that microbial communities evolve as their host evolves and has been confirmed to exist for certain insects and mammals. Researchers recently tested whether that relationship holds among fish. Approximately 420 million years ago, fish made an epic evolutionary split into elasmobranchs - creatures with all-cartilage skeletons - and bony fish. Since then, the two have accumulated vast differences in anatomy and physiology, most notably in their skin. That's where the researchers zeroed in. For a small sample of fish, they used metagenomics to compare the makeup of microbial communities living on fish skin. Between fishes considered closely or distantly related in evolutionary terms, findings revealed that elasmobranchs displayed patterns of phylosymbiosis, while bony fish did not. A difference that might be linked to alternative processes of microbiome assembly. Scaling up to a larger sample size could offer researchers further insight and help explain the skin microbiome dynamics of marine fishes. 